\title{
Assessment of nasopharyngeal Streptococcus pneumoniae colonization does not permit discrimination between Canadian children with viral and bacterial respiratory infection: a matched-cohort cross-sectional study
}

Jeffrey M. Pernica ${ }^{1 *}$, Kristin Inch ${ }^{1}$, Haifa Alfaraidi ${ }^{1,2}$, Ania Van Meer ${ }^{1}$, Redjana Carciumaru ${ }^{1}$, Kathy Luinstra ${ }^{3}$ and Marek Smieja $a^{3,4}$

\begin{abstract}
Background: Readily-available diagnostics do not reliably discriminate between viral and bacterial pediatric uncomplicated pneumonia, both of which are common. Some have suggested that assessment of pneumococcal carriage could be used to identify those children with bacterial pneumonia. The objective of this study was to determine if nasopharyngeal pneumococcal colonization patterns differed between children with definite viral disease, definite bacterial disease, and respiratory disease of indeterminate etiology.

Methods: Three groups of subjects were recruited: children with critical respiratory illness, previously healthy children with respiratory illness admitted to the ward, and previously healthy children diagnosed in the emergency department with non-severe pneumonia. Subjects were categorized as follows: a) viral infection syndrome (eg. bronchiolitis), b) bacterial infection syndrome (ie. pneumonia complicated by effusion/empyema), or c) 'indeterminate' pneumonia. Subjects' nasopharyngeal swabs underwent quantitative PCR testing for S. pneumoniae. Associations between categorical variables were determined with Fisher's exact, chi-square, or logistic regression, as appropriate. Associations between quantitative genomic load and categorical variables was determined by linear regression.
\end{abstract}

Results: There were 206 children in Group 1, 122 children in Group 2, and 179 children in Group 3. Only a minority $(227 / 507,45 \%)$ had detectable pneumococcal carriage; in those subjects, there was no association of quantitative genomic load with age, recruitment group, or disease category. In multivariate logistic regression, pneumococcal colonization $>3 \log$ copies $/ \mathrm{mL}$ was associated with younger age and recruitment group, but not with disease category.

\footnotetext{
* Correspondence: pernica@mcmaster.ca

'Department of Pediatrics, McMaster University, 1280 Main St. West, Hamilton, Ontario L8S 4K1, Canada

Full list of author information is available at the end of the article
}

(c) The Author(s). 2021 Open Access This article is licensed under a Creative Commons Attribution 4.0 International License, which permits use, sharing, adaptation, distribution and reproduction in any medium or format, as long as you give appropriate credit to the original author(s) and the source, provide a link to the Creative Commons licence, and indicate if changes were made. The images or other third party material in this article are included in the article's Creative Commons licence, unless indicated otherwise in a credit line to the material. If material is not included in the article's Creative Commons licence and your intended use is not permitted by statutory regulation or exceeds the permitted use, you will need to obtain permission directly from the copyright holder. To view a copy of this licence, visit http://creativecommons.org/licenses/by/4.0/ The Creative Commons Public Domain Dedication waiver (http://creativecommons.org/publicdomain/zero/1.0/) applies to the data made available in this article, unless otherwise stated in a credit line to the data. 
Conclusions: The nasopharyngeal S. pneumoniae colonization patterns of subjects with definite viral infection were very similar to colonization patterns of those with definite bacterial infection or indeterminate pneumonia. Assessment and quantification of nasopharyngeal pneumococcal colonization does not therefore appear useful to discriminate between acute viral and bacterial respiratory disease; consequently, this diagnostic testing is unlikely to reliably determine which children with indeterminate pneumonia have a bacterial etiology and/or require antibiotic treatment.

Keywords: Diagnostic microbiology, Pneumonia, Respiratory tract infection, Epidemiology, Streptococcus pneumoniae

\section{Summary}

Our results do not support the use of the assessment and quantification of nasopharyngeal pneumococcal colonization to discriminate between children with viral and bacterial respiratory disease.

\section{Introduction}

Pneumonia is one of the leading causes of paediatric hospitalization in North America. The causes of pneumonia in childhood are many and varied, with viruses, typical bacteria, and atypical pathogens (eg. Mycoplasma pneumoniae) all playing important roles [1]. The principles of supportive care for children with respiratory disease, such as the provision of oxygen or ventilatory support, are similar regardless of microbiologic etiology; however, bacterial pneumonia should be treated with appropriate antimicrobials to mitigate disease impact [2]. Consequently, the identification of bacterial respiratory infection is important to facilitate optimal patient management. It is generally accepted that Streptococcus pneumoniae is the pathogen that accounts for most severe bacterial community-acquired pneumonia in children, with its identification and treatment of high importance to clinicians [2-4].

Unfortunately, the microbiologic diagnosis of indeterminate (not obviously viral or bacterial) paediatric respiratory infection is not readily accomplished without resorting to highly invasive testing, such as percutaneous trans-thoracic lung aspiration [4]. Nasopharyngeal testing for viruses and atypical pathogens using molecular methods has high sensitivity and specificity [5], but the identification of a viral/atypical pathogen in the nasopharynx does not preclude bacterial co- or superinfection, a common occurrence [1, 6-8]. White blood counts and serum C-reactive protein are weakly predictive of bacterial etiology [2], whereas blood cultures are very specific but insensitive for the detection of bacterial pneumonia [9]. There is substantial inter- and intraobserver variability in the assessment of chest radiographs [10-13], such that their ability to reliably discriminate between bacterial/atypical/viral infection is very limited. Current pneumonia treatment guidelines emphasize that pneumonia in preschoolers often has a viral etiology and does not necessarily warrant treatment $[2,3]$, but antibiotics are prescribed to most anyway [14]; this may be because clinicians and parents are more concerned about missing a potentially serious bacterial infection than the harms of antimicrobials. As a result, the need for better diagnostics to improve antimicrobial stewardship, even in younger age groups, has been highlighted [15].

Some have recommended measuring pneumococcal nasopharyngeal carriage to discriminate between viral and bacterial infection; cut-offs of $3 \log$ copies $/ \mathrm{mL}$ [16], $3.9 \log$ copies $/ \mathrm{mL}$ [17], and $6.9 \log$ copies/mL [18] have been proposed to better identify adults and children with pneumococcal disease. If nasopharyngeal pneumococcal genomic loads were truly higher in children with pneumococcal pneumonia, the most important bacterial pneumonia pathogen $[2,4,15]$, this diagnostic test could be used to discriminate between children with primary viral pneumonia and those with bacterial pneumonia, thereby facilitating clinical management and decisions about antibiotic therapy. The objective of this study was to determine if patterns of nasopharyngeal pneumococcal carriage differed amongst children in Canada with definite viral disease, definite bacterial disease, and respiratory disease of indeterminate etiology; it should be emphasized the latter category accounts for the majority of episodes of pediatric community-acquired pneumonia in North America $[1,19,20]$.

\section{Materials and methods}

There were three groups of children recruited for this study. Please note that 'respiratory illness' was defined as 'because of perceived respiratory disease (ie. with signs or symptoms of respiratory distress) or requiring either supplemental oxygen or assisted ventilation.'

1. Group 1 consisted of all children aged 2 mos $-18 \mathrm{y}$ admitted to the paediatric intensive care unit (PICU) of McMaster Children's Hospital (MCH) because of respiratory illness between Sept 2015Oct 2016 and had a nasopharyngeal swab (NPS) performed less than a week after admission, as previously described, through retrospective review [21]. 
2. Group 2 consisted of previously healthy children aged 2 mos -18 y admitted to the general paediatric wards because of respiratory illness from Sept 2015-Jan 2020 prospectively identified through convenience sampling. Those with ventilatorassociated pneumonia, cystic fibrosis, anatomic lung disease, bronchiectasis, congenital heart disease, history of repeated aspiration, malignancy, conditions requiring treatment with immune suppressants, or primary immunodeficiency were excluded.

3. Group 3 consisted of previously healthy children aged 6 mos - 10 y who were diagnosed with community-acquired pneumonia in the $\mathrm{MCH}$ Emergency Department (ED) and were well enough to be managed as outpatients, as previously described, in a prospective randomized trial [22]. Participants were enrolled during Dec 2012-March 2014 (pilot phase) and Aug 2016-Dec 2019.

Children were categorized into the following disease categories based on discharge diagnoses made by the clinical team and interpretation of chest radiographs made by the attending radiologist:

a) Viral infection syndrome (eg. bronchiolitis, asthma exacerbation without a secondary diagnosis of bacterial pneumonia and without a chest radiograph consistent with pneumonia). Current guidelines strongly recommend against treating these children with antimicrobials regardless of illness severity [23, 24].

b) Bacterial infection syndrome, ie. pneumonia complicated by effusion/empyema (identified by lung ultrasound).

c) 'Indeterminate' pneumonia characterized by a clinical diagnosis of pneumonia but without effusion/empyema. Many of these children would have had pure viral infections, but a substantial proportion likely also had bacterial co-infection, as identification of the causative pathogen(s) is generally not feasible [1, 6-8]. As this disease category was of particular interest, it was further subdivided into 'non-severe' (ie. did not require hospital admission) and 'severe' (ie. was hospitalized).

Please note that the vast majority of children in the 'viral infection syndrome' and 'bacterial infection syndrome' categories did not require microbiologic confirmation. For example, it is recommended not to do microbiologic testing in children with clinically-diagnosed bronchiolitis [23, 24 ], and the majority of cases of pneumonia complicated by effusion are known to have a bacterial cause $[19,25]$.
$\mathrm{MCH}$ is a tertiary children's hospital in Hamilton, Ontario, Canada; at the time of the study, the hospital had 259 beds, approximately 6500 admissions, and approximately 40,000 ED visits yearly. All children hospitalized with a potentially infectious respiratory illness at $\mathrm{MCH}$ have an NPS performed routinely to identify respiratory viruses, as per the institutional Acute Respiratory Infection Surveillance Protocol.

For each patient, a nasopharyngeal flocked swab (FLOQSwab, Copan Italia, Brescia, Italy) was collected in $3 \mathrm{~mL}$ of Universal Transport Medium (UTM, Copan Italia). Samples were stored at negative $80 \mathrm{C}$ until testing to preserve sample integrity. After vortexing, 200uL of NPS sample was extracted by easyMag (bioMérieux, St.Laurent, Quebec, Canada) and eluted in 55uL. Five uL of the eluate was amplified for $S$. pneumoniae using previously published primer and probe sequences [26]. The assay amplifies a $101 \mathrm{bp}$ sequence targeting lyt $A$, the autolysin gene. The real-time qPCR assay was run on the Rotor-Gene Q (Qiagen, Germantown, USA) using the QuantiTect Probe PCR Kit (Qiagen). Each reaction contained $5 \mathrm{uL}$ of extracted nucleic acid in a final reaction volume of 20uL, 1X QuantiTect Probe PCR Master Mix, $0.4 \mathrm{uM}$ of the forward and reverse primers and 0.1 $\mathrm{uM}$ of the TaqMan probe. The probe was labeled with FAM and TAMRA. The assay conditions were $95^{\circ} \mathrm{C}$ for 15 min for initial PCR activation followed by 45 cycles of denaturation at $95^{\circ} \mathrm{C}$ for $5 \mathrm{~s}$ with a combined annealing and extension step at $62{ }^{\circ} \mathrm{C}$ for $45 \mathrm{~s}$. Cycle threshold (CTs) values below 40 cycles were considered positive. To verify the specificity of the assay, $20 \mathrm{~S}$. pneumoniae positive controls including two ATCC strains, 49619 and 6305 and 18 clinical and laboratory isolates plus 25 negative control organisms, encompassing respiratory organisms and isolates and other streptococcal species were assessed. No cross reactivity was noted with the primers and probes with the viridans group streptococci isolates tested (three different $S$. mitis isolates). In the absence of $S$. pseudopneumoniae strains, the potential cross reactivity of the assay with $S$. pseudopneumoniae could not be ruled out.

Positive samples were further quantified using a standard curve generated from 10-fold serial dilutions of a lyt $A$ cloned control ranging from $10^{2}$ to $10^{6}$ copies/reaction. The cloned control consisted of a $553 \mathrm{bp}$ amplified segment of the lytA gene of S. pneumoniae ATCC 49619 inserted into a pGEM ${ }^{\oplus}$ T Easy Vector (Promega, Madison, WI). All generated standard curves had slopes between -3.4 and -3.2 , and $R^{2}$ values $>0.96$ and $<1$.

The main outcome was nasopharyngeal pneumococcal genomic load. The covariates of interest were disease category, age (categorized into clinically relevant groups), hospitalization status, and group of recruitment. We did not address potential sources of bias in the 
analysis, including potential selection bias in groups 2 (ward) and 3 (ED), and did not adjust the analyses for additional potential confounders. Descriptive statistics with appropriate measures of central tendency were presented for all study subjects. Normality was assessed visually. Chi-square or Fisher exact testing, as appropriate, was done to compare categorical variables. Forward logistic regression was done in a stepwise fashion adding covariates found to be significant with $p<0.2$ in bivariate analyses; those associated with a statistically significant change in the -2log likelihood of the model were retained. No imputation of missing data was done. Analyses were done using STATA v11.2 (College Station, TX). No formal sample size calculation was done in this exploratory study utilizing convenience sampling.

\section{Results}

There were 206 children recruited to Group 1 (PICU), 122 children recruited to Group 2 (hospitalized on ward), and 179 children recruited to Group 3 (ED). The median participant age was 2.5 years (25-75\%ile $1.3-4.9$ y). There were 160 (32\%) with a definite viral infection syndrome, 179 (35\%) with non-severe indeterminate pneumonia, 134 (26\%) with indeterminate pneumonia who were hospitalized, and $34(6.7 \%)$ with definite bacterial infection (complicated pneumonia). The distribution of the outcome variable of interest, pneumococcal genomic load, was not normal, as a majority of subjects (280/507, 55\%) did not have pneumococci detected in their NPS. However, the distribution of genomic load in those with detectable carriage was roughly normal. There were 286 (56\%) participants with 0-3 log copies/ $\mathrm{mL}, 153$ (30\%) with 3-6.9 $\log$ copies/mL, and 68 (13\%) with $>6.9 \log$ copies $/ \mathrm{mL}$ in their NPS.

Younger participants were more likely to have detectable pneumococcal carriage. Of those aged $<5$ years, 190 (50\%) had 0-3 log copies/mL, 127 (33\%) had 3-6.9 log copies/mL, and $65(17 \%)$ had $>6.9 \log$ copies/mL in their NPS; in contrast, in those aged 5 and over, 96 (77\%) had 0-3 log copies/mL, 25 (20\%) had 3-6.9 log copies $/ \mathrm{mL}$, and $3(2.4 \%)$ had $>6.9 \log$ copies $/ \mathrm{mL}(p<$ $0.0001)$. However, among those with $S$. pneumoniae detected, quantitative genomic load was not associated with age (ie. younger children did not have numerically higher pneumococcal loads). Carriage rate also varied by recruitment group; 67\% of Group 1 (PICU), 53\% of Group 2 (ward), and $42 \%$ of Group 3 (ED) did not have $S$. pneumoniae detected $(p<0.001)$. It should be noted, however, that the age distribution of participants was different in different groups. The quantitative genomic load among those with detectable carriage was similar between participants of different groups.

Participants with definite bacterial disease (ie. complicated pneumonia) had very similar colonization patterns as compared to participants with definite viral disease (eg. bronchiolitis) (Table 1). However, it was found that participants with non-severe indeterminate pneumonia had higher carriage rates than participants in other disease categories. In those with detectable carriage, the quantitative genomic load was similar between subjects of all different disease categories.

Given that age category, recruitment group, and disease category appeared to all be associated with the presence of pneumococcal nasopharyngeal carriage ( $>3 \mathrm{log}$ copies $/ \mathrm{mL}$ ), these covariates were entered into the logistic regression model. In this multivariable model, we found that age category continued to exert a dominant effect on the likelihood of colonization; furthermore, the effect of recruitment group was slightly diminished, but was still statistically significant. When age and recruitment group were taken into account, there was no significant residual association between nasopharyngeal pneumococcal carriage and disease category (Table 2).

\section{Discussion}

In this study, we did not find any association between respiratory disease category and S. pneumoniae nasopharyngeal carriage $>3 \log$ copies $/ \mathrm{mL}$, or pneumococcal quantitative genomic load, when the effects of age and location of recruitment were adjusted for. If quantitation of pneumococcal carriage at admission to hospital could not distinguish between definite viral disease (eg. bronchiolitis) and definite bacterial disease (ie. pneumonia complicated by effusion), it seems unreasonable to posit that this diagnostic testing could be used to determine which children with indeterminate pneumonia had a viral, as compared to bacterial, cause. Our results also do not support the idea of using this diagnostic test as a supplementary diagnostic aid for epidemiologic studies of children presenting with respiratory disease.

Pneumococcal colonization precedes and is presumably a prerequisite for disease caused by $S$. pneumoniae [27]; consequently, it is reasonable to posit that carriage would be more common or nasopharyngeal genomic loads would be higher in those children with pneumococcal infection as compared to those without. This has indeed been demonstrated in multiple different studies of children living in low- and middle-income countries $[16,18,28-30]$. The seminal PERCH case-control study, enrolling in Bangladesh, the Gambia, Kenya, Mali, South Africa, Thailand, and Zambia, found that 56 cases with pneumococcal pneumonia had substantially higher nasopharyngeal pneumococcal genomic loads than 4035 children without pneumococcal disease, with the optimal discriminatory cut-off being $6.9 \log$ copies/mL [18]. One study of 550 consecutive children admitted to a Vietnamese hospital found that those with radiographicallyconfirmed pneumonia were less likely to be colonized 
Table 1 Comparison of subjects in different diagnostic disease categories

\begin{tabular}{|c|c|c|c|c|}
\hline & $\begin{array}{l}\text { Viral infection } \\
\text { syndrome } \\
(n=160)\end{array}$ & $\begin{array}{l}\text { Pneumonia, } \\
\text { indeterminate, } \\
\text { nonsevere } \\
(n=179)\end{array}$ & $\begin{array}{l}\text { Pneumonia, } \\
\text { indeterminate, } \\
\text { severe } \\
(n=134)\end{array}$ & $\begin{array}{l}\text { Bacterial } \\
\text { infection } \\
\text { syndrome } \\
(n=34)\end{array}$ \\
\hline \multicolumn{5}{|l|}{ Age category } \\
\hline$<2 y$ & $93(58 \%)$ & $76(43 \%)$ & 49 (37\%) & $2(5.9 \%)$ \\
\hline 2 to $<5 y$ & $36(22 \%)$ & $65(37 \%)$ & $43(32 \%)$ & $18(53 \%)$ \\
\hline 5 to $<10 y$ & $22(14 \%)$ & $36(20 \%)$ & $26(19 \%)$ & $8(24 \%)$ \\
\hline $10 y$ and over & $9(5.6 \%)$ & $1(0.56 \%)$ & $16(12 \%)$ & $6(18 \%)$ \\
\hline \multicolumn{5}{|l|}{ Pneumococcus detected? } \\
\hline Yes & $63(39 \%)$ & $103(58 \%)$ & $48(36 \%)$ & $13(38 \%)$ \\
\hline No & $97(61 \%)$ & $76(42 \%)$ & $86(64 \%)$ & $21(62 \%)$ \\
\hline $\begin{array}{l}\text { Median genomic load ( } 25-75 \% \text { ile) in those with detectable } \\
\text { pneumococcal colonization, log copies/mL }\end{array}$ & $6.12(4.63-6.89)$ & $6.30(5.06-7.17)$ & $5.80(5.30-6.94)$ & $6.26(5.05-7.63)$ \\
\hline \multicolumn{5}{|l|}{ Pneumococcal genomic load } \\
\hline 0-3 log copies/mL & $98(61 \%)$ & $80(45 \%)$ & $87(65 \%)$ & $21(62 \%)$ \\
\hline 3-6.9 log copies/mL & $48(30 \%)$ & $61(34 \%)$ & $35(26 \%)$ & $9(26 \%)$ \\
\hline$>6.9 \log$ copies/mL & $14(8.8 \%)$ & $38(21 \%)$ & $12(9.0 \%)$ & $4(12 \%)$ \\
\hline
\end{tabular}

Bold indicates differences between categories, $p<0.001$

with S. pneumoniae than healthy controls; however, those children with pneumonia had higher nasopharyngeal genomic loads than those with other types of respiratory infection or healthy controls [28]. Smaller studies in Mozambique and the Gambia found that paediatric cases with invasive pneumococcal disease or pneumococcal pneumonia had similar colonization rates but higher nasopharyngeal genomic loads than healthy controls $[29,30]$. As a result, it has been suggested that the assessment of pneumococcal nasopharyngeal carriage could be used to discriminate between children with and without pneumococcal pneumonia; however, our experience suggests that this may not be true in Canada, and therefore it may not be true in other regions.

The likelihood that $S$. pneumoniae will be detectable in the nasopharynx of a given individual depends on a great number of factors, including age, genetics, socioeconomic conditions, crowding in the home, daycare exposure, and many more [27]. Age is simple to ascertain

Table 2 Associations with nasopharyngeal pneumococcal colonization > 3 log copies $/ \mathrm{mL}$

\begin{tabular}{|c|c|c|c|c|}
\hline \multirow[t]{2}{*}{ Covariate } & \multicolumn{2}{|c|}{ Bivariate analyses } & \multicolumn{2}{|c|}{ Multivariate analyses } \\
\hline & OR $(95 \% \mathrm{Cl})$ & Wald $p$ & OR $(95 \% \mathrm{Cl})$ & Wald $p$ \\
\hline \multicolumn{5}{|l|}{ Age category } \\
\hline$<2 y$ & ref & & ref & \\
\hline 2 to $<5 y$ & $1.27(0.85-1.90)$ & 0.25 & $1.28(0.83-1.97)$ & 0.27 \\
\hline 5 to $<10 y$ & $0.39(0.23-0.66)$ & 0.001 & $0.39(0.22-0.68)$ & 0.001 \\
\hline $10 y$ and over & $0.16(0.053-0.46)$ & 0.001 & $0.22(0.072-0.68)$ & 0.008 \\
\hline \multicolumn{5}{|l|}{ Recruitment group } \\
\hline 1 (PICU) & ref & & ref & \\
\hline 2 (ward) & $1.80(1.14-2.85)$ & 0.012 & $1.54(0.94-2.53)$ & 0.09 \\
\hline 3 (ED) & $2.62(1.73-3.98)$ & $<0.001$ & $2.20(1.36-3.55)$ & 0.001 \\
\hline \multicolumn{5}{|l|}{ Disease category } \\
\hline Viral infection syndrome & ref & & NS & \\
\hline Nonsevere indeterminate pneumo. & $1.96(1.27-3.02)$ & 0.002 & & \\
\hline Severe indeterminate pneumonia & $0.85(0.53-1.38)$ & 0.52 & & \\
\hline Bacterial infection syndrome & $0.98(0.46-2.10)$ & 0.96 & & \\
\hline
\end{tabular}


and appears to play a very prominent role; pneumococcal nasopharyngeal colonization is rapidly acquired during infancy and early childhood and then slowly declines thereafter [27]. In our study, we also observed a clear association between pneumococcal carriage and age. It has also been observed in multiple studies that pneumococcal carriage rates increase with/after respiratory viral infection in children [16, 31-33]. It may be that the combination of these factors play a role in explaining why assessment of nasopharyngeal $S$. pneumoniae colonization did not permit the discrimination of those with bacterial respiratory disease from those with viral disease in our study population.

Our study did have limitations. We did not enroll consecutive children in Cohorts 2 (ward) and 3 (ED), primarily due to resource constraints; these were convenience samples, and so we cannot exclude the possibility of selection bias. We also did not include severity of disease, duration of illness, receipt of antimicrobials prior to nasopharyngeal sampling, sociodemographic factors, daycare exposure, household crowding, genetic factors, vaccination status, and a host of other putative exposures and unmeasured confounders that could possibly influence pneumococcal carriage. Consequently, we cannot exclude the possibility that pneumococcal carriage would in fact be associated with respiratory disease category when these additional factors are taken into account. However, we would suggest that many of these are not practical to measure on a regular basis by clinicians evaluating children with respiratory disease, and so would not impact our recommendations that nasopharyngeal S. pneumoniae genomic loads not be routinely used to diagnose bacterial lung infection. In other words, if pneumococcal nasopharyngeal loads were in fact associated with bacterial infection controlling for disease severity, duration of illness, receipt of antimicrobials prior to nasopharyngeal sampling, age, socioeconomic status, number of people in the home, and vaccination status, this would likely not change our conclusion that S. pneumoniae nasopharyngeal PCR is not a practical way to diagnose bacterial pneumonia in individual children in an urgent-care setting. Finally, given that diagnoses were made on a clinical basis (as is the standard of care in North America), we could not prove that the proportion of children with viral disease in the 'viral syndrome' group was higher than in the 'indeterminate' group or the 'bacterial syndrome' group; however, this seems exceedingly likely to be true. We would also posit that this consideration is irrelevant, since Canadian physicians routinely make clinical diagnoses without microbiologic confirmation that then inform antibiotic treatment decisions; the aim of this study was to determine if quantitative assessment of nasopharyngeal pneumococcal colonization could aid this diagnostic process, thereby potentially optimizing antimicrobial treatment practices.

\section{Conclusions}

In summary, our matched-cohort study demonstrates that quantitative assessment of nasopharyngeal S. pneumoniae carriage is unlikely to be of practical help to clinicians seeking to determine whether a given child has viral or bacterial respiratory infection.

\begin{abstract}
Acknowledgments
Not applicable.

Authors' contributions

JMP conceived the study, helped with study design, did data analysis, drafted the manuscript, and revised the manuscript critically. Kl, HA, and AVM helped with study design, data collection, and revised the manuscript critically. RC helped with data collection and revised the manuscript critically. $\mathrm{KL}$ and MS designed the microbiologic assays, ran them, and revised the manuscript critically. The author(s) read and approved the final manuscript.

\section{Funding}

This work was supported by the Physician's Services Incorporated Foundation (Clinical Research Grant 14-34) and McMaster University Department of Pediatrics Resident Research Grants (AVM, Kl, HA). JMP was supported by a Hamilton Health Sciences Early Career Award.
\end{abstract}

Availability of data and materials

The datasets used are available from the corresponding author on reasonable request.

\section{Declarations}

\section{Ethics approval and consent to participate}

The study was approved by the Hamilton Integrated Research Ethics Board and informed consent was obtained from all participants (and from the parents/legal guardians for those aged less than 18 years) who were recruited and followed prospectively (ie. Group 2 and 3), some of whom were drawn from other studies [21, 22]. All methods were performed in accordance with the Declaration of Helsinki.

Consent for publication

Not applicable.

\section{Competing interests}

The authors declare that they have no competing interests.

\section{Author details}

'Department of Pediatrics, McMaster University, 1280 Main St. West, Hamilton, Ontario L8S 4K1, Canada. ${ }^{2}$ Present address: Department of Pediatrics, King Saud bin Abdulaziz University for Health Sciences, King Abdullah Specialized Children's Hospital, Ministry of the National Guard Health Affairs, Riyadh, Saudi Arabia. ${ }^{3}$ Department of Laboratory Medicine, St. Joseph's Healthcare Hamilton, 50 Charlton Ave. E, Hamilton, Ontario L8N 4A6, Canada. ${ }^{4}$ Department of Pathology and Molecular Medicine, McMaster University, Hamilton, Canada.

Received: 26 January 2021 Accepted: 21 May 2021

Published online: 31 May 2021

\section{References}

1. Jain S, Williams DJ, Arnold SR, Ampofo K, Bramley AM, Reed C, et al. Community-acquired pneumonia requiring hospitalization among U.S. children. N Engl J Med. 2015;372(9):835-45. https://doi.org/10.1056/ NEJMoa1405870.

2. Bradley JS, Byington CL, Shah SS, Alverson B, Carter ER, Harrison C, et al. The management of community-acquired pneumonia in infants and children older than 3 months of age: clinical practice guidelines by the PIDS and IDSA. Clin Infect Dis. 2011;53(7):e25-76. https://doi.org/10.1093/cid/cir531.

3. Le Saux N, Robinson JL, Canadian Paediatric Society Infectious Disease and Immunization Committee. Uncomplicated pneumonia in healthy Canadian children and youth: practice points for management. Paediatr Child Health. 2015;20(8):441-50. https://doi.org/10.1093/pch/20.8.441. 
4. Ebruke BE, Knoll MD, Haddix M, Zaman SMA, Prosperi C, Feikin DR, et al. The Aetiology of pneumonia from analysis of lung aspirate and pleural fluid samples: findings from the PERCH study. Clin infect Dis. 2020. https://doi. org/10.1093/cid/ciaa1032.

5. Gill PJ, Richardson SE, Ostrow O, Friedman JN. Testing for respiratory viruses in children: to swab or not to swab. JAMA Pediatr. 2017;171(8):798-804. https://doi.org/10.1001/jamapediatrics.2017.0786.

6. Nolan VG, Arnold SR, Bramley AM, Ampofo K, Williams DJ, Grijalva CG, et al. Etiology and impact of coinfections in children hospitalized with community-acquired pneumonia. J Infect Dis. 2018;218(2):179-88. https:// doi.org/10.1093/infdis/jix641.

7. Gavrieli H, Dagan R, Givon-Lavi N, Ben-Shimol S, Greenberg D. Unique features of hospitalized children with alveolar pneumonia suggest frequent viral-bacterial coinfections. Pediatr Infect Dis J. 2020;39(7):586-90. https://doi. org/10.1097/INF.0000000000002639

8. Thorburn K, Riordan A. Pulmonary bacterial coinfection in infants and children with viral respiratory infection. Expert Rev Anti-Infect Ther. 2012; 10(8):909-16. https://doi.org/10.1586/eri.12.80.

9. Neuman MI, Hall M, Lipsett SC, Hersh AL, Williams DJ, Gerber JS, et al. Utility of Blood Culture Among Children Hospitalized With Community-Acquired Pneumonia. Pediatrics. 2017;140(3):e20171013.

10. Xavier-Souza G, Vilas-Boas AL, Fontoura MS, Araujo-Neto CA, Andrade SC, Cardoso MR, et al. The inter-observer variation of chest radiograph reading in acute lower respiratory tract infection among children. Pediatr Pulmonol. 2013:48(5):464-9. https://doi.org/10.1002/ppul.22644.

11. Neuman MI, Lee E, Bixby S, Diperna S, Hellinger J, Markowitz R, et al. Variability in the interpretation of chest radiographs for the diagnosis of pneumonia in children. J Hospital Med. 2012;7(4):294-8. https://doi.org/10.1 002/jhm.955.

12. Johnson J, Kline JA. Intraobserver and interobserver agreement of the interpretation of pediatric chest radiographs. Emerg Radiol. 2010;17(4):28590. https://doi.org/10.1007/s10140-009-0854-2.

13. Andronikou S, Lambert E, Halton J, Hilder L, Crumley I, Lyttle MD, et al. Guidelines for the use of chest radiographs in community-acquired pneumonia in children and adolescents. Pediatr Radiol. 2017:47(11):1405-11. https://doi.org/10.1007/s00247-017-3944-4

14. Florin TA, Byczkowski T, Gerber JS, Ruddy R, Kuppermann N. Diagnostic testing and antibiotic use in young children with community-acquired pneumonia in the United States, 2008-2015. J Pediatric Infect Dis Soc. 2020; 9(2):248-52. https://doi.org/10.1093/jpids/piz026.

15. Katz SE, Williams DJ. Pediatric community-acquired pneumonia in the United States: changing epidemiology, diagnostic and therapeutic challenges, and areas for future research. Infect Dis Clin N Am. 2018;32(1): 47-63. https://doi.org/10.1016/j.idc.2017.11.002.

16. Wolter N, Tempia S, Cohen C, Madhi SA, Venter M, Moyes J, et al. High nasopharyngeal pneumococcal density, increased by viral coinfection, is associated with invasive pneumococcal pneumonia. J Infect Dis. 2014; 210(10):1649-57. https://doi.org/10.1093/infdis/jiu326.

17. Albrich WC, Madhi SA, Adrian PV, van Niekerk N, Mareletsi T, Cutland C, et al. Use of a rapid test of pneumococcal colonization density to diagnose pneumococcal pneumonia. Clin Infect Dis. 2012;54(5):601-9. https://doi. org/10.1093/cid/cir859.

18. Baggett HC, Watson NL, Deloria Knoll M, Brooks WA, Feikin DR, Hammitt LL, et al. Density of Upper Respiratory Colonization With Streptococcus pneumoniae and Its Role in the Diagnosis of Pneumococcal Pneumonia Among Children Aged $<5$ Years in the PERCH Study. Clin Infect Dis. 2017; 64(suppl_3):S317-S27.

19. Cherry JD, Harrison GJ, Kaplan SL, Steinbach WJ, Hotez PJ. Feigin and Cherry's Textbook of Pediatric Infectious Diseases. 8th ed: Elsevier; 2019.

20. Lipsett SC, Hall M, Ambroggio L, Hersh AL, Shah SS, Brogan TV, et al. Antibiotic choice and clinical outcomes in ambulatory children with community-acquired pneumonia. J Pediatr. 2021;229:207-15 e1. https://doi. org/10.1016/j.jpeds.2020.10.005

21. Alfaraidi H, Luinstra K, Eshaghi A, Smieja M, Gubbay JB, Pernica JM. Paediatric critical illness associated with respiratory infection: a singleCentre, retrospective cohort study. BMJ Paediatr Open. 2020;4(1):e000640. https://doi.org/10.1136/bmjpo-2020-000640.

22. Pernica JM, Harman S, Kam AJ, Carciumaru R, Vanniyasingam T, Crawford T, et al. Short-course antimicrobial therapy for pediatric community-acquired pneumonia: the SAFER randomized clinical trial. JAMA Pediatr. 2021;175(5): 475-82. https://doi.org/10.1001/jamapediatrics.2020.6735.
23. Ralston SL, Lieberthal AS, Meissner HC, Alverson BK, Baley JE, Gadomski AM, Johnson DW, Light MJ, Maraqa NF, Mendonca EA, Phelan KJ, Zorc JJ, Stanko-Lopp D, Brown MA, Nathanson I, Rosenblum E, 3rd Sayles S, Hernandez-Cancio S, American Academy of Pediatrics Clinical practice guideline: the diagnosis, management, and prevention of bronchiolitis. Pediatrics. 2014;134(5):e1474-e1502, DOI: https://doi.org/10.1542/peds.2 014-2742.

24. Friedman JN, Rieder MJ, Walton JM, Canadian Paediatric society ACCDT, Hazardous Substances C. Bronchiolitis: recommendations for diagnosis, monitoring and management of children one to 24 months of age. Paediatr Child Health. 2014;19(9):485-98. https://doi.org/10.1093/pch/19.9.4 85.

25. Pernica JM, Moldovan I, Chan F, Slinger R. Real-time polymerase chain reaction for microbiological diagnosis of parapneumonic effusions in Canadian children. Can J Infect Dis Med Microbiol. 2014:25(3):151-4.

26. McAvin JC, Reilly PA, Roudabush RM, Barnes WJ, Salmen A, Jackson GW, et al. Sensitive and specific method for rapid identification of Streptococcus pneumoniae using real-time fluorescence PCR. J Clin Microbiol. 2001;39(10): 3446-51. https://doi.org/10.1128/JCM.39.10.3446-3451.2001.

27. Garcia-Rodriguez JA, Fresnadillo Martinez MJ. Dynamics of nasopharyngeal colonization by potential respiratory pathogens. J Antimicrobial Chemotherapy. 2002;50 Suppl S2:59-73.

28. Vu HT, Yoshida LM, Suzuki M, Nguyen HA, Nguyen CD, Nguyen AT, et al. Association between nasopharyngeal load of Streptococcus pneumoniae, viral coinfection, and radiologically confirmed pneumonia in Vietnamese children. Pediatr Infect Dis J. 2011;30(1):11-8. https://doi.org/10.1097/INF. Ob013e3181f111a2.

29. Dunne EM, Hua Y, Salaudeen R, Hossain I, Ndiaye M, Ortika BD, et al. Insights into pneumococcal pneumonia using lung aspirates and nasopharyngeal swabs collected from pneumonia patients in the Gambia. J Infect Dis. 2020. https://doi.org/10.1093/infdis/jiaa186.

30. Brotons P, Bassat Q, Lanaspa M, Henares D, Perez-Arguello A, Madrid L, et al. Nasopharyngeal bacterial load as a marker for rapid and easy diagnosis of invasive pneumococcal disease in children from Mozambique. PLoS One. 2017;12(9):e0184762. https://doi.org/10.1371/journal.pone.0184762.

31. Grijalva CG, Griffin MR, Edwards KM, Williams JV, Gil Al, Verastegui H, et al. The role of influenza and parainfluenza infections in nasopharyngeal pneumococcal acquisition among young children. Clin Infect Dis. 2014; 58(10):1369-76. https://doi.org/10.1093/cid/ciu148.

32. Fan RR, Howard LM, Griffin MR, Edwards KM, Zhu Y, Williams JV, et al. Nasopharyngeal pneumococcal density and evolution of acute respiratory illnesses in young children, Peru, 2009-2011. Emerg Infect Dis. 2016;22(11): 1996-9. https://doi.org/10.3201/eid2211.160902.

33. Thors V, Christensen H, Morales-Aza B, Oliver E, Sikora P, Vipond I, et al. High-density bacterial nasal carriage in children is transient and associated with respiratory viral infections-implications for transmission dynamics. Pediatr Infect Dis J. 2019;38(5):533-8. https://doi.org/10.1097/INF. 0000000000002256

\section{Publisher's Note}

Springer Nature remains neutral with regard to jurisdictional claims in published maps and institutional affiliations.

Ready to submit your research? Choose BMC and benefit from:

- fast, convenient online submission

- thorough peer review by experienced researchers in your field

- rapid publication on acceptance

- support for research data, including large and complex data types

- gold Open Access which fosters wider collaboration and increased citations

- maximum visibility for your research: over $100 \mathrm{M}$ website views per year

At BMC, research is always in progress.

Learn more biomedcentral.com/submissions 